\title{
Phỏng sinh học trong y dược học - Hướng nghiên cứu cần được đẩy mạnh
}

\author{
Nguyễn Thanh Hải ${ }^{1, *}$, Bùi Thanh Tùng ${ }^{1}$, Phạm Thị Minh Huệ ${ }^{2}$ \\ ${ }^{I}$ Khoa Y Duợc, Đại học Quốc gia, Hà Nội, 144 Xuân Thủy, Cầu Giấy, Hà Nội, Việt Nam \\ ${ }^{2}$ Truờng ĐH Dược Hà Nội, 13-15 Lê Thánh Tông, Hà Nội, Việt Nam
}

Nhận ngày 24 tháng 3 năm 2017

Chỉnh sửa ngày 19 tháng 4 năm 2017; Chấp nhận đăng ngày 14 tháng 6 năm 2017

\begin{abstract}
Tóm tắt: Phỏng sinh học là một ngành khoa học công nghệ có tính hấp dẫn cao và có tác động lớn tới hầu hết các hoạt động của cuộc sống và sản xuất, từ phát triển sản xuất các thiết bị và đồ dùng dân dụng trên cơ sở các nguyên lý cơ học cổ điển cho đến các lĩnh vực hiện đại như robot, chip điện tử, công nghệ nano ... Trong y dược học, các phương pháp phỏng sinh học cũng có giá trị lớn trong việc phát triển thuốc, phát triển các phương pháp trong chẩn đoán, phòng tránh và điều trị bệnh tật. Ứng dụng phỏng sinh học trong y dược học là một hướng nghiên cứu có rất nhiều triển vọng cả về tính ưu việt, tính khả thi và tính bền vững. Việc xem xét và ứng dụng các phương pháp của ngành phỏng sinh học chắc chắn sẽ tạo ra các tiển bộ mới không chỉ với các phương pháp hiện tại mà cả trong việc cải tiến các phương pháp đã có. Trong quá trình phát triển thuốc, việc học tập sinh giới nhằm tìm ra các dược liệu mới và tác dụng mới là một phương pháp có tính khả thi và tính hiệu quả cao. Lời giải của các bài toán lớn của khoa học y dược như giải phóng thuốc đúng nơi, đúng liều và đúng lúc, chắn chắn cũng sẽ tìm thấy một cách thuận lợi hơn, nếu sử dụng các dữ liệu của tự nhiên. Hình thành và đẩy mạnh nghiên cứu phỏng sinh học trong bào chế có thể là một hướng đi mới tạo ra được bướt tiến mới cho khoa học sức khỏe.
\end{abstract}

Từ khóa: Phỏng sinh học, phỏng sinh học bào chế, sinh giới.

\section{Giới thiệu}

Phỏng sinh học (Bionics/Biomimetics) là ngành khoa học công nghệ chuyên nghiên cứu các chức năng, đặc điểm và hiện tượng... của sinh vật trong tự nhiên và mô phỏng các khả năng đặc biệt đó để thiết kế, chế tạo các hệ thống kỹ thuật và công nghệ hiện đại, hữu ích nhằm cải tiến hoạt động và đáp ứng nhu cầu của con người. Thuật ngữ "biomimetics" do một bác sĩ người Mỹ, Jack. E. Steel, đưa ra vào năm 1958. Mặc dù là một ngành khoa học có lịch sử chưa dài, nhưng có tính hẩp dẫn cao và có tác động rất lớn tới sản xuất và đời sống con người [1].

\footnotetext{
Tác giả liên hệ. ĐT.: 84-913512599.

Email: haipharm@yahoo.com

https://doi.org/10.25073/2588-1132/vnumps.4070
}

Phương pháp của phỏng sinh học là sao chép một cách có ý thức các hiện tượng, cơ chế của sinh vật, tự nhiên và hệ sinh thái. Như vậy thiên nhiên được xem là nguồn cơ sở dữ liệu và tập hợp giải pháp cho các vấn đề. Điều này cho thấy, khoa học công nghệ phỏng sinh học cực kỳ rộng lớn và có tính bền vững cao. Dựa trên các cấp độ sinh học của sinh giới, có thể phân ra 3 mức độ phỏng sinh học:

- Bắt chước phương pháp sản xuất trong tự nhiên.

- Sao chép cấu trúc tìm thấy trong tự nhiên, sử dụng các vật liệu trong tự nhiên.

- Nghiên cứu các nguyên tắc tổ chức từ các hành vi xã hội của sinh vật như: hành vi sống, hành vi tổ chức ... [2]. 
Trên thực tế phòng sinh học được ứng dụng và thể hiện tính hiệu quả cao trong hầu hết các hoạt động của cuộc sống, từ phát triển sản xuất các thiết bi đồ dùng dân dụng trên cơ sở các nguyên lý cơ học cổ điển cho đến các lĩnh vực hiện đại như robot, chip điện tử, công nghệ nano ... [2].

\section{Phỏng sinh học trong y dược học}

Trong y dược học, lĩnh vực đi tiên phong trong việc nghiên cứu phát triển và ứng dụng các thành tự khoa học công nghệ tiên tiến để phục vụ lợi ích con người, phương pháp phỏng sinh học cũng đã được sử dụng phổ biến và cho rất nhiều mục tiêu khác nhau.

Trong quá trình chẩn trị bệnh, cha ông ta cũng đã vận dụng rất tài tình các qui luật, hiện tượng tự nhiên để mang lại lợi ích cho con người trong việc cứu chữa và bảo vệ sức khỏe. Các học thuyết như âm dương ngũ hành, hàn nhiệt, tương sinh tương khắc, khí huyết, kinh lạc, huyệt đạo, thiền định hòa nhập với thiên nhiên ... là những minh chứng rõ nét cho sự vận dụng sáng tạo đó.

Trong quá trình tìm tòi cây thuốc, cha ông ta cũng đã áp dụng thành công các phương pháp phỏng sinh học trong nhiều trường hợp. Nhiều cây thuốc quí, có giá trị cao trong điều trị, đã được tìm ra nhờ áp dụng các phương pháp này [3]. Một số ví dụ điển hình có thể kể đến là: phát hiện ra tác dụng chữa bệnh của cây Hoàn ngọc (cây Con Khỉ - Khi xưa có một người đàn ông chuyên vào rừng sâu để nhặt củi. Một hôm, ông nhìn thấy khỉ mẹ chữa khỏi bệnh thủng ruột cho khỉ con bằng lá cây Tu Lình. Ông đem câu chuyện này kể cho người dân trong làng nghe và người ta đã đặt tên cho cây thuốc đó là cây con khỉ (Theo truyền thuyết dân gian)); cây Diệp hạ châu (cây Chó đẻ răng cưa - tên gọi như vậy vì từ xa xưa các bậc chân y đã quan sát và thấy, sau khi sinh, chó mẹ thường tìm ăn loại cây này); Dâm dương hoắc (cây cho lá, dê hay ăn, mà dê lại có ham muốn tình dục cao - Đỗ Tất Lợi (tái bản 2003), Những cây thuốc và vị thuốc Việt Nam tr. 905-906)... [3].
Trước đây biomimetics có nghĩa là thay thế hoặc tăng cường hoạt động các cơ quan hoặc các bộ phận cơ thể bằng cách sử dụng các phiên bản cơ khí. Với hướng này, $\mathrm{y}$ học đã tạo ra nhiều thành tựu, nhiều sản phẩm, giúp duy trì các chức năng sinh lý và tăng cường sức khỏe con người. Sau này, trong quá trình phát triển, rất nhiều thuật ngữ và ý nghĩa mới đã được hình thành và phát triển gắn với biomimetics. Các thuật ngữ khác có liên quan có thể kể đến như: biomimetic brain, biomimetic human, biomimetic models, biomimetic body, biomimetic pancreas system, biomimetic eye, biomimetic spinal cord... Đây chắc chắn đều là những ngành khoa học công nghệ mới, rất lý thú, và hứa hẹn nhiều phát kiến và thành tựu mới. Các nghiên cứu gần đây về đặc điểm sinh học của các tế bào ung thư, tế bào gốc; cơ chế sinh sản; cơ chế thực bào ... đã tạo ra những bước tiến lớn trong y học [4].

Thuật ngữ biomimetic cấy ghép (biomimetic implant), chính là cách bắt chước để thay thế nhằm duy trì chức năng ban đầu của các bộ phận cơ thể một cách chặt chẽ, hoặc thậm chí vượt trội. Mặc dù các công nghệ cấy ghép biomimetic vẫn còn trong thời kỳ sơ khai, nhưng cũng đã xuất hiện một vài sản phẩm điển hình nhu: ốc tai điện tử (thiết bị dành cho người khiếm thính); tim nhân tạo đầy đủ chức năng; võng mạc nhân tạo; bàn tay nhân tạo [4]; hồng cầu nhân tạo [5].

Trong lịch sử phát triển của y dược học hiện đại, nhiều ý tưởng đã được hình thành và có ảnh hưởng lớn tới tiến trình phát triển. Một trong những ý tưởng đó là thuốc tác dụng tại đích của nhà khoa học đoạt giải Nobel, Paul Ehrlich (1854 - 1915). Trên cơ sở các quan sát trong quá trình nghiên cứu phân loại vi sinh vật, ông đã đưa ra ý tưởng là có những phân tử thuốc chỉ tác dụng tới đích gây bệnh mà không có tác dụng tới các đích hoặc mô bình thường của cơ thể $[6,7]$. Ý tưởng vĩ đại đó của ông đã được rất nhiều nhà khoa học theo đuổi, tuy nhiên cho đến nay, khoa học chỉ mới thừa nhận hai phân tử có tính chất gần đáp ứng được với các tiêu chí Ông đưa ra, đó là: penicillin và kháng thể. Để tiếp tục phát triển ý tưởng của Paul Ehrlich, thành công nhiều hơn có lẽ thuộc 
về các nhà khoa học bào chế với việc phát triển các dạng bào chế giải phóng dược chất tại đích (thuốc tới đích) $[2,8]$. Nhiều thuốc, đặc biệt các thuốc có độc tính cao, đã được phát triển dưới dạng này, giúp tăng cường sinh khả dụng và giảm độc tính một cách rõ ràng. Các dạng bào chế hiện đại, phát triển gần đây, ứng dụng nhiều kiến thức, kỹ thuật liên quan đến phỏng sinh học, đã giúp phát triển các thuốc tới đích có những ưu điểm vượt trội. Một số ví dụ điển hình như: sử dụng các nguyên liệu, chất mang có nguồn gốc tự nhiên (như phospholipid); mô phỏng các cấu trúc tự nhiên (liposome, phytosome có cấu tạo tương tự màng tế bào; các cấu trúc nano kiểu dendramer...) [9-11]; tạo lớp vỏ có khả năng tránh bi thực bào; tìm tới đích theo cơ chế kháng nguyên - kháng thể... [6, 7].

Trong thời gian vừa qua, các nhà khoa học trong nước đã triển khai một số hướng nghiên cứu theo định hướng phỏng sinh học bằng cách sử dụng các nguyên liệu có nguồn gốc sinh học, mô phỏng các cấu trúc sinh học để phát triển các dạng bào chế có sinh khả dụng ưu việt, giúp góp phần giải quyết nhiều vấn đề mà dược học hiện đại đang đặt ra. Trên thực tế, trong quá trình áp dụng trong lâm sàng, nhiều dược chất bào chế dưới dạng thuốc quy ước (truyền thống) vấp phải rất nhiều trở ngại do các dược chất có độc tính cao, nhiều tác dụng không mong muốn, sinh khả dụng thấp, kém ổn định... Để vượt qua các trở ngại đó, dạng thuốc tới đích là dạng bào chế lý tưởng để phát triển. Trong số các cấu trúc mang thuốc tới đích, phương pháp phỏng sinh học theo các cấu trúc tương tự các màng sinh học và cấu trúc sinh học ngày càng được nghiên cứu và cải tiến nhiều. Bằng cách đó, có thể tạo ra các dạng thuốc có tính tương hợp sinh học cao; có khả năng phân huỷ sinh học; không gây ra phản ứng kháng nguyên - kháng thể; không gây phản ứng dị ứng và giảm độc tính [12]. Liposome và phytosome là các hệ mang thuốc đáp ứng các mục tiêu đó, và cùng sử dụng tá dược phospholipid là thành phần chính. Nhiều hợp chất có nguồn gốc tự nhiên, có tác dụng sinh học quý, nhưng ứng dụng vào thực tiễn lâm sàng chỉ cho ích lợi nhỏ, do kém ổn định, khó hấp thu qua màng sinh học và nhanh đào thải khỏi cơ thể. Các hoạt chất hoặc các nhóm hoạt chất đó có thể được tạo phức với phospholipid để thay đổi đặc tính hòa tan và phân bố trong pha nước và pha dầu, giúp tăng hấp thu, giảm độc tính, kéo dài tác dụng. Dạng bào chế này đã hình thành nên một dòng sản phẩm mới là phytosome. Nhiều hoạt chất, tách chiết từ dược liệu, đã được phát triển thành công thành các sản phẩm có giá trị điều trị cao dưới dạng phytosome [12].

\section{Kết luận}

Úng dụng phỏng sinh học trong y dược học là một hướng nghiên cứu có rất nhiều triển vọng, cả về tính ưu việt, tính khả thi và tính bền vững. Việc xem xét và ứng dụng các phương pháp của ngành phỏng sinh học chắc chắn sẽ tạo ra các tiến bộ mới không chỉ với các phương pháp hiện tại mà cả trong việc cải tiến các phương pháp đã có. Sử dụng các phương pháp phỏng sinh học trong các nghiên cứu hướng tới các lĩnh vực như chẩn đoán, phòng tránh, điều trị, phát triển thuốc mới là rất cần thiết, nhằm xây dựng nên các quan điểm và định hướng mới trong giải quyết các vấn đề liên quan đến sức khỏe con người một cách tự nhiên và bền vững hơn.

Trong quá trình phát triển thuốc, việc học tập sinh giới nhằm tìm ra các dược liệu mới và tác dụng mới, là một phương pháp có tính khả thi và tính hiệu quả cao. Lời giải của các bài toán lớn của khoa học y dược như giải phóng thuốc đúng nơi, đúng liều và đúng lúc chắn chắn cũng sẽ tìm thấy một cách thuận lợi hơn nếu sử dụng các dữ liệu của tự nhiên. Hình thành và đẩy mạnh nghiên cứu phỏng sinh học bào chế có thể là một hướng đi tạo ra được bướt tiến mới trong khoa học sức khỏe.

\section{Tài liệu tham khảo}

[1] Vincent Julian Fv, Bogatyreva Olga A, Bogatyrev Nikolaj R, Bowyer Adrian, Pahl Anja-Karina. Biomimetics: its practice and 
theory. Journal of the Royal Society Interface 3(9) (2006) 471.

[2] Hwang Jangsun, Jeong Yoon, Park Jeong Min, Lee Kwan Hong, Hong Jong Wook, Choi Jonghoon. Biomimetics: forecasting the future of science, engineering, and medicine. International journal of nanomedicine 10((2015) 5701.

[3] Valko Klara. Physicochemical and biomimetic properties in drug discovery: chromatographic techniques for lead optimization. John Wiley \& Sons (2013).

[4] Bar-Cohen Yoseph. Biomimetics-biologically inspired technologies CRC Press. Boca Raton(2006).

[5] Nguyễn Thị Thanh Thủy, Trịnh Ngọc Dương, Nguyễn Thị Thanh Bình, Bùi Thanh Tùng, Nguyễn Thanh Hải. Chất vận chuyển oxy Perfluorocarbon và triển vọng phát triển hồng cầu nhân tạo,. Tạp chí Khoa học Đại học Quốc gia Hà Nội - Khoa học Y Dược, 32(2) (2016) 1

[6] Từ Minh Koóng, Nguyễn Thanh Hải. Thuốc tới đích. Tạp chí Dược học 388(8) (2008) 1.
[7] Từ Minh Koóng, Nguyễn Thanh Hải. Thuốc tới đích. Tạp chí Dược học 389(9) (2008) 2.

[8] Gorb Stanislav N. Biological attachment devices: exploring nature's diversity for biomimetics. Philosophical Transactions of the Royal Society of London A: Mathematical, Physical and Engineering Sciences 366(1870) (2008) 1557.

[9] Từ Minh Koóng, Nguyễn Thanh Hải. Công nghệ nano và sản xuất dược phẩm. Tạp chí Dược học 369(1) (2007) 2.

[10] Từ Minh Koóng, Nguyễn Thanh Hải. Công nghệ nano và sản xuất dược phẩm. , Tạp chí Dược học 370(2) (2007) 3.

[11] Từ Minh Koóng, Nguyễn Thanh Hải. Công nghệ nano và sản xuất dược phẩm. Tạp chí Dược học 371(3) (2007) 4.

[12] Phạm Thị Minh Huệ, Nguyễn Thanh Hải, Võ Xuân Minh. Phytosome: Giải pháp tăng sinh khả dụng cho các hoạt chất có nguồn gốc dược liệu. Tạp chí Dược học 465(1) (2015) 2.

\title{
Biomimetics in Medicine and Pharmacy - New Perpectives Should be Strengthed
}

\author{
Nguyen Thanh Hai ${ }^{1}$, Bui Thanh Tung ${ }^{1}$, Pham Thi Minh Hue ${ }^{2}$ \\ ${ }^{1}$ VNU Hanoi School of Medicine and Pharmacy, 144 Xuan Thuy, Cau Giay, Hanoi, Vietnam \\ ${ }^{2}$ Hanoi University of Pharmacy, 13-15 Le Thanh Tong, Hanoi, Vietnam
}

\begin{abstract}
Biomimetics (or bionics) is a highly attractive scientific field. It has a great impact on almost every aspect of life, from the development of consumer devices on the basis of classical mechanical principles to modern fields like robot, electronic chip, nano technology... In the field of medicine and pharmacy, biomimetic methods are of great value in developing drugs, developing methods for the diagnosis, prevention and treatment diseases. The application of biomimetics in the field of medicine and pharmacy is a promising prospect in terms of superiority, feasibility and sustainability. The consideration and application of the biomimetic methods will undoubtedly generate new advances not only in current methods, but also in the improvement of existing methods. In the field of drug development, the study of the biological world in order to find new pharmaceutical raw materials and new effective action is a feasible and highly effective method. The solution to major problems of pharmaceutical science, such as releasing drugs in the right place, at the correct dose and in time, will certainly find a better way by using the data of nature. Formation and promotion of biomimetic - pharmaceutics can be a new direction for new advances in health sciences.
\end{abstract}

Keywords: Biomimetics; Bionics; Biomimetic - pharmaceutics; Biological system. 